\title{
ir
}

\section{LAS VERSIONES DE ZARAGOZA Y MADRID DE LA VIDA ES SUEÑO: CONTINUIDAD Y RUPTURA}

\author{
Ysla Campbell \\ Universidad Autónoma de Ciudad Juárez \\ [Anuario calderoniano (ISSN: 1888-8046), 1, 2008, pp. 67-85]
}

En La vida es sueño ${ }^{1}$ existe una dicotomía política: por un lado, el maquiavelismo del rey Basilio, secundado por Clotaldo; por otro, el tacitismo de Segismundo. Todo ello dentro del marco de la filosofia neoestoica que privilegia el racionalismo al servicio de la virtud en una lucha constante contra las pasiones.

La idea de comparar ambas versiones tiene como objetivo ver la continuidad o la ruptura en los planteamientos político-filosóficos antes enunciados. José María Ruano de la Haza considera que los textos manifiestan en Calderón «los cambios experimentados por su arte e ideología entre dos períodos diferentes de su vida» ${ }^{2}$. El análisis de las variantes permite, más que percibir modificaciones en las tendencias políticas y filosóficas (neoestoicismo y tacitismo) ver el paso del mundo particular español hacia un importante universalismo. Evidentemente hay una mayor precisión en la edición de Madrid de errores

${ }^{1}$ Edición de José María Ruano de la Haza.

2 Ruano de la Haza, 1992, p. 27. Aunque conozco la polémica, no es mi intención abordar el problema sobre la edición inicial. Ambas fueron publicadas en 1636, pero la versión de Madrid fue aprobada primero, en 1635. 
evidentes ${ }^{3}$ o cambios $^{4}$ que, en muchas ocasiones, poco afectan a la semántica global del texto.

Las transformaciones más palpables y profundas, en cuanto al tema que nos interesa, se dan en varios sentidos: por una parte, la caracterización de los personajes; por otra, la perspectiva ideológica que los mueve. En principio cabría preguntarnos sobre la relación entre el conflicto personal de Basilio con su hijo y la cuestión del gobierno. En el primer acto de la versión de Zaragoza encontramos a un rey aparentemente afligido por el destino de Polonia, sin embargo, una vez enfrentado al príncipe, sólo se lamenta de su propia desgracia: «Yo mismo, yo, mi muerte he pretendido / mi mortaja tejí, gusano he sido" (vv. 2428-2429). En el nivel del discurso, Basilio manifiesta a la corte su preocupación por la patria, pero en el momento de la acción sólo revela su profundo temor a la muerte. Lipsio opina que el fingimiento es uno de los principales enemigos de la constancia; expresa al respecto: «Oh buenos hombres, comedia representáis, y enmascarados con la máscara de la patria, lloráis con verdaderas y vivas lágrimas vuestros daños particulares» ${ }^{5}$. A pesar de que en sentido similar se expone la intranquilidad del rey en la versión madrileña, difiere de la anterior: "Con lo que yo guardaba me he perdido; / yo mismo, yo, mi patria he destruido» (vv. 2458-2459). En el primer caso la preocupación del monarca es por la propia muerte, lo que produce una autodenigración al compararse con una oruga que se arrastra, denota humildad y abatimiento al perecer atrapada en su propia red; en el segundo, se reconoce que el procedimiento empleado para quedar invicto fue erróneo, lo que provocó serios conflictos al Estado. La calificación del rey pasa de un rebajamiento personal a la toma de conciencia de una equivocación. Entre ambas actitudes hay una diferencia radical del concepto de los personajes sobre sí mismos. Cuando van a salir a la guerra, se dice respectivamente:

${ }^{3}$ Por ejemplo, en la versión de Zaragoza dice Rosaura: «Con asombros de escucharte, / con admiración de oírte» (vv. 249-250); en la de Madrid cambia a «Con asombro de mirarte» (v. 243), por la repetición de los elementos auditivos.

${ }^{4}$ En Z escribe: «tú volviste en alegría» (v. 2087); en M varía: «tú trocaste en alegría” (v. 2123).

5 Libro de la constancia de Justo Lipsio, p. 25 (BNM, R. 19024). 
Dadme un caballo y mi vejez cansada salga a postrar un hijo inobediente.

Lo que el consejo erró, pueda la espada; o cumpla el cielo ya el hado inclemente.

(Z, vv. 2438-2441)

Dadme un caballo, porque yo en persona vencer valiente a un hijo ingrato quiero; y en la defensa ya de mi corona, lo que la ciencia erró venza el acero.

(M, vv. 2484-2487)

En los versos iniciales se advierte una visión de Basilio que se centra, de nuevo, en cuestiones netamente individuales, como la autocompasión por la debilidad propia de su edad, en quien existe la duda sobre la factibilidad de derrotar al hijo «inobediente», que, incluso, no menciona su interés por defender el trono. El propio Maquiavelo, refiriéndose a los ministros, sostiene: «quien administra el poder de otro no debe jamás pensar en sí» ${ }^{6}$. En la edición madrileña se presenta, por el contrario, un rey fuerte y decidido que se enfrenta a las circunstancias, a quien, si no le fue posible vencer a Segismundo mediante la ciencia, intentará hacerlo, movido por la conservación del poder, con las armas. Además, hay una gran diferencia entre la desobediencia y la ingratitud con que se califica al príncipe, pues si bien el sometimiento al padre era un valor de suma importancia en la época, la ingratitud rebasa dichos límites; es concebida por Séneca como un acto deleznable que, en este caso, apoya la actitud resuelta de Basilio. Dice el filósofo cordobés: «ser agradecido es una virtud: has restituido una cosa banal y has conseguido otra inapreciable, la conciencia del agradecimiento que no alcanza sino el alma divina y afortunada». Y añade que «nada hay más hermoso que un espíritu agradecido» ${ }^{7}$. La asociación de esta virtud con la divinidad manifiesta su elevada ponderación. Lo que mueve a los hombres a ser ingratos es la codicia de los favores que esperamos recibir. La idea de la ingratitud es la que motiva en Basilio para luchar contra su hijo, ya que el deseo de éste es sacar verdaderos a los cielos, es decir, proclamarse rey y desti-

${ }^{6}$ Maquiavelo, El príncipe, p. 136.

7 Séneca, De los beneficios y la gratitud que se les debe, t. II, pp. 24-25; 27. 
tuir a su padre deshonrosamente. Hay, pues, un planteamiento político coherente.

Es notorio el distinto papel que en ambos textos juega la ciencia. En la versión de Zaragoza los deudos de Basilio no lo distinguen como científico en el primer encuentro - Astolfo y Estrella se dirigen a él en términos afectivos-, es el propio rey quien debe referir su interés en dicha área del conocimiento. A eso se suma que, al explicar su intento a la corte y hacer la petición de que avalen su experimento, en el orden de los versos se subordina el papel de sabio al de anciano (rey, padre, anciano, sabio, esclavo). El mismo monarca resta importancia a la función de la ciencia y sólo llega a desengañarse de persuasiones menos específicas: «lo que el consejo erró». En la edición de Madrid hay mayores elementos, como la recepción de los cortesanos, el hecho de que Basilio se jacte de su sabiduría, el orden de los versos, de ahí que se llegue a la idea de que la "ciencia erró».

Por otro lado, cuando Basilio se retira de la torre después de que el príncipe despierta, Crotaldo señala en un aparte: «(... Fuese el Rey; que la piedad / más lágrimas no podía reprimir»; vv. 2106-2108). En la versión madrileña indica: «Enternecido se ha ido / el Rey de haberle escuchado"; vv. 2138-2139). Las palabras del privado muestran un personaje que manifiesta sus sentimientos hasta el llanto, causa de su alejamiento; en las segundas, Basilio no va más allá de la ternura. Al desatarse la guerra inicia preguntándose en la versión de Zaragoza: «¿Hay padre más desdichado?» (v. 3079), y una vez derrotado dice: «Segismundo, si a tu padre / y a tu rey busca tu saña» (vv. 3154-3155). El interrogante no existe en la versión madrileña y los otros versos se modificaron: «Si a mí buscándome vas, / ya estoy, príncipe, a tus plantas» (vv. 3146-3147). Su posición es distinta, pues en el primer caso se da prioridad a la relación filial sobre la política y viceversa.

Estos elementos caracterizan un rey abatido y sentimental que si bien no descartan su concepción maquiavélica, le restan fuerza. Sigue al pensador florentino en los procedimientos engañosos, en justificarse por una razón de Estado, en no creer en el libre albedrío, en partir de que los hombres son malos desde su nacimiento. Su objetivo de quedar como rey invicto también será relativizado en el contexto global de la obra, como observaremos adelante. Además, cuando habla a la corte dice: "que tirano con mi hijo» (v. 777), y al plantear el regreso del príncipe a la torre, reconoce: «pues lo que hoy es tiranía / 
entonces será castigo» (vv. 820-821). Concepciones que se eliminaron de la otra versión: «que si es tirano mi hijo» (v. 777); "siendo, el volverle a la cárcel, / no crueldad, sino castigo» (vv. 824-825). La definición de Basilio sobre sus actos contra Segismundo como tiranía revela una faceta que se elude en la obra de Madrid, donde el único tirano posible es Segismundo.

La incredulidad del monarca en el libre albedrío, a pesar de que se define a Lutero como mentiroso (v. 1347), también tiene otras connotaciones, ya que hay una idea bipolar sobre la divinidad. En las décimas que el príncipe dirige al cielo, cuestiona: «¿En qué ley, en qué razón, / divina o humana, cabe» (vv. 183-184). En la edición de Madrid, pregunta: «¿Qué ley, justicia, o razón / negar a los hombres sabe» (vv. 167-168). Clotaldo dice «cielo airado» — «hado triste» en M-, «...jcielo impío!» (v. 941) — «Mal resisto...» en M-. Segismundo, después de encomendar a la divinidad a Astolfo le "Vuelve las espaldas», de acuerdo con la didascalia, situación que no sólo denota descortesía en el personaje, sino que resta importancia al carácter religioso, erasmista, del saludo. Rosaura declara que estaría «triste, afligida y quejosa» (v. 2841), si fuera a un convento. Estos últimos señalamientos (acotación y verso) no aparecen en la edición de Madrid. En resumen, se culpa a Dios antes que a los hombres, encomendar a Él es una fórmula y hay un rechazo a dedicarse a servirlo. Por otro lado, aun cuando Clotaldo se refiera al cielo en el sentido cosmológico o, de acuerdo con Covarrubias, con una expresión común (el aire), en el mismo texto se asevera que la divinidad es quien dispone el orden del universo, por lo tanto otorgar pasiones o atribuir impiedad al cielo revela cierta irreverencia. Hay, pues, un contraste entre un Dios que nunca engaña al conformar los astros y escribir en el "cielo», en el que debe creerse, incluso Segismundo en la torre, que da libre albedrío al hombre, y otro que se asemeja al Jehová del Antiguo Testamento en Z. No es fortuito que Calderón haya eliminado esa perspectiva ambivalente.

Clotaldo, definido por Alcalá-Zamora como personificación incondicional del concepto de Basilio sobre el Estado ${ }^{8}$, es decir, sin consideraciones morales, es fiel a la visión política maquiavélica reinante que priva en la edición madrileña — aunque en ambos textos no com-

${ }^{8}$ Alcalá-Zamora, 1989, p. 42. 
parte la opinión del soberano sobre el papel del libre albedrío-. No sucede lo mismo en la versión de Zaragoza, donde encontramos un personaje que expresa varios parlamentos cargados de sensibilidad en relación con su hija y con el príncipe. Al referirse a Rosaura, quien puede ser condenada a muerte, dice: «Ese joven / —mal las lágrimas reprimo- (vv. 870-871); en la edición de Madrid, en lugar del verso que entraña un sentimiento de dolor, califica al hijo: «Este bello joven, / osado o inadvertido» (vv. 870-871). Adelante, al lograr el perdón del rey para su hijo, manifiesta en la zaragozana: «Bien, rendido corazón, / del primer lance salimos» (vv. 888-889); mientras que en la madrileña asume una actitud oportunista: «(Mejoró el cielo la suerte; / ya no diré que es mi hijo, / pues que lo puedo escusar»; vv. 890892). Es notorio que se produce un cambio en la caracterización de Clotaldo, ya que hay versos que se eliminan, como cuando expresa muy líricamente siguiendo a Garcilaso: «iAy, hija desdichada! / ¡Ay, dulce prenda, / por mi mal hallada!» (vv. 1660-1661).

Respecto a la relación de Clotaldo con Segismundo, en el palacio, el regresar a tranquilizarlo, dice: «Vuelvo desesperado, / que es mi príncipe en fin y le he criado" (vv. 1634-1635). La inquietud se debe al afecto del privado por el sucesor. De igual forma, en el palacio éste pregunta a Clotaldo cómo ha llegado hasta allí, ya que está amenazando a Rosaura, le responde: «De los afectos de mi amor llevado» (v. 1683); en la edición de Madrid, en cambio, contesta: «De los acentos desta voz llamado» (v. 1675). Por otra parte, en la versión de Zaragoza se reitera su disponibilidad de morir tanto por Rosaura como por Segismundo. Cuando éste quiere matarlo, dice a su hija: «Tú, Rosaura, / deja mi vida, mas tu honor restaura» (vv. 1694-1695); y luego que Astolfo, armado, interviene para detenerlo, le pide: «Menos importa, Astolfo, que yo muera; / no le ofendas, detente, aguarda, espera» (vv. 1712-1713); después repite la misma idea al rey, que es la única que aparece en la edición de Madrid. No presenciamos, pues, un Clotaldo frío y calculador al servicio de la administración, sino un padre conmovido por la situación de su hija y angustiado por las circunstancias de su casi hijo y discípulo Segismundo, a quien habla de su afecto y cuya vida protege, sin que esto reste su lealtad al soberano.

Recordemos que en la concepción lipsiana el hombre se compone de un alma, por la que pelea la razón, y de un cuerpo por el que pelea la opinión. En este contexto, el príncipe también presenta va- 
riantes notables en tanto que aparece como un personaje dominado, de manera más marcada, por la pasión corporal. En el protagonista se manifiesta un aire de erotismo, mediante la alusión a la experiencia sensual, que fue eliminado de la edición madrileña. Segismundo, por ejemplo, confiesa que hubiera sido capaz de soportar la privación de la libertad con una mujer hermosa, como Estrella, a su lado; le comenta:

\author{
$\mathrm{Y}$ a mi padre perdonara \\ que cruel conmigo fuera, \\ cuando en el monte tuviera \\ una hermosura tan rara. \\ Mas ¿qué crueldad pudo haber \\ que más admire ni asombre \\ que haberle negado a un hombre \\ la beldad de una mujer?
}

(vv. 1406-1413)

La inhumanidad de Basilio por su trato y encerramiento en la torre la reduce a la carencia de una mujer, sin importar la libertad, las relaciones sociales y el conocimiento de su origen aunado a su derecho de sucesión. De forma similar, ante Rosaura afirma la posibilidad de perder "a tu respeto el miedo» (v. 1649), en tanto que en la edición madrileña el texto se matiza al referirlo a la "hermosura» de la dama. Una vez liberado por los soldados, al ver a Rosaura, lo primero que expresa es: «Todo cuanto soñé, cumplido veo; / éste es el triunfo y gloria que deseo" (vv. 2664-2665). Sus objetivos políticos o de lucha desaparecen ante la protagonista, pues su pasión por ella lo lleva a concluir que esa es la verdadera conquista. En la edición madrileña, que carece de tales versos, lo primero que Segismundo se plantea es la relación entre la realidad y el sueño, se contrasta el conocimiento sobre lo ocurrido en el palacio. Una vez que el príncipe sabe el problema de Rosaura, en el texto de Zaragoza, después de autoconvencerse de no gozarla y sopesar la trascendencia de otros valores, justifica, en términos que revelan la concepción de la época, su propio rechazo:

Fuera de que, aunque me veo más enamorado agora de Rosaura, no sé bien 
qué veneno o qué ponzoña
en mi pecho ha introducido
la relación de su historia
que, con amor y sin gusto,
la miro. ¡Qué baja cosa
debe de ser en el mundo,
en materias amorosas,
amar lo que otro olvida
o querer lo que otro goza!

(vv. 2980-2991)

Tal perspectiva sobre el amor, que desapareció de $\mathrm{M}$, permite comprender mejor la actitud pasional y las acciones de Rosaura, así como el apoyo y el consejo de su madre. La idea de que amar a una mujer deshonrada - con una referencia sexual carente de finura- es una bajeza que envenena el corazón, su rechazo total, su disgusto, restan fuerza a su conversión final: el vencimiento de sí mismo. El carácter prioritario de esta prueba en su lucha contra las pasiones pierde vigor. Su decisión de devolver el honor a la dama casándola tiene menos peso, pues es dificil, para el espectador, que ya ha escuchado el repudio del príncipe, creer que en la última escena esté dominando sus sentimientos; no se presencia una verdadera lucha interior de renuncia ante el objeto amado, como ocurre en la edición madrileña. En ésta el concepto de Segismundo sobre Rosaura no ha cambiado, de ahí que sea más verosímil su actitud de no verla y el vencimiento de sí mismo cuando determina desposarla con Astolfo. En resumen, hay otros valores en el personaje coherentes con todo el proceso de transición de la pasión a la virtud que cuestionan la idea del período sobre la mujer deshonrada.

Al finalizar el acto segundo, en el parlamento del príncipe, que es muy breve (doce versos), no hay reflexión alguna sobre lo efimero de los bienes terrenales, como se da en la edición de Madrid (cuarenta versos). Este tema, esencial en relación con los verdaderos bienes (interiores) planteados por el neoestoicismo, al no ser desarrollado, impide que Segismundo sea consciente del escaso valor de los falsos bienes (materiales), de ahí que cuando está al mando del ejército y llega a sitiar el recinto real, exclame al verlo: "iAh vida de palacio, / emulación del orbe de topacio!» (vv. 2618-2619). La comparación es muy elocuente, así como la forma de expresarla, hay un gusto y una ad- 
miración nacidos de su experiencia pasada, que lo inducen a establecer un símil entre el mundo cortesano y la mítica isla de Topacio. Situada en el mar Bermejo, debía su nombre a dichas piedras, y dado que siempre estaba cubierta de niebla, a los navegantes les resultaba casi imposible descubrirla ${ }^{9}$. La dificultad para llegar a las anheladas gemas es semejante a la del príncipe para vivir en el palacio. En esta versión estamos frente a un personaje más ligado a lo material, mundo del que logra desprenderse en la edición de Madrid.

El concepto del amor trae como consecuencia que en el vencimiento de las pasiones se dé más importancia al dominio de la ira, la vanagloria y el deseo de venganza. En general, se enfatizan las pasiones de Rosaura y Segismundo; por ejemplo, las intenciones de la protagonista son matar a Astolfo y vengarse, Clotaldo califica este acto como «furia» (vv. 2590, 2608); confiesa estar celosa de Estrella; Segismundo, en un aparte, habla de su "cólera» e «iras» con Clotaldo, porque no va a ayudarlo. En la edición madrileña, aunque Rosaura expresa su idea de matar al duque, no aparece la palabra vengarse; en vez de furia dice "desatino»; y los otros versos fueron omitidos. Asimismo, Estrella admite tener "celos» (v. 2445), término que no se usa en la edición de Madrid. En ambos textos se manejan las pasiones como parte fundamental de la conducta de los personajes, sin embargo, el empleo de un léxico específico es más recurrente en la versión de Zaragoza que en la de Madrid, lo que da mesura y elegancia a ésta sin restar profundidad.

En lo que respecta a la participación del pueblo y de sus representantes, los soldados 1 y 2 , es más amplia en $\mathrm{Z}$. Las finalidades de la lucha son tener un príncipe natural y alcanzar la libertad: el soldado 2 dice "que aclaman la libertad» (v. 2234). Ambos objetivos, para Segismundo, están íntimamente relacionados; afirma: «En mí tenéis / quien os libre, osado y diestro, / de extranjera sucesión» (vv. 22962298). No obstante, el deseo de libertad del pueblo no es tan simple de interpretar, ya que el propio Basilio, como vimos, se denomina tirano con su hijo. De donde puede deducirse un sentimiento de opresión generalizado.

Dentro de los códigos de valor sobresalientes en la versión antigua se da una importancia capital al factor de integración por excelencia

9 Covarrubias, Tesoro. 
de la sociedad española de la época: el honor. Si bien en ambas obras se presenta el problema de la mujer deshonrada (Violante y Rosaura), la pérdida del honor se lleva al extremo en la de Zaragoza, pues recae en la máxima autoridad, representante terrenal de Dios, y es una línea ideológica que marca notoriamente la versión. En el acto III se da un planteamiento de la trascendencia de dicha cuestión; Clotaldo expresa: "Con mi mismo honor peleo; / con mi mismo agravio lucho. / ¿Qué haré? Mas, viva el honor, / siempre honor, siempre leal» (vv. 2480-2483). Asimismo, según Segismundo, la gravedad de las consecuencias de las acciones de Basilio es similar a los que se arrojan "contra honor, ser, vida y honra» (v. 3218) —en la edición de Madrid los primeros versos de omitieron y en los segundos alude a fiera, espada y borrasca (vv. 3206-3209) - . De tal forma, atentar contra el valor más alto de la sociedad española conduce, necesariamente, a su pérdida, aunque se trate del soberano.

En la disputa sobre la lealtad, entablada entre los soldados y Clotaldo, se considera que éste actúa contra el «bien común». El protagonista replica a la respuesta del privado:

Clotaldo,

si os parece esto lo cierto,

idos a servir al Rey

vos, leal, prudente y cuerdo.

Pero no arguyáis a nadie

si es bien hecho o mal hecho,

que todos tienen honor.

(vv. 2362-2368)

De acuerdo con José María Ruano de la Haza ${ }^{10}$ «Esta declaración de que todos tienen honor y que, por tanto, no es lícito imponer una moral absoluta ("bien hecho, o mal hecho") revelan un Segismundo maquiavélico, para quien las consideraciones éticas son secundarias al pragmatismo político». La crítica del príncipe a Clotaldo se dirige al levantamiento contra Basilio: el privado no tiene derecho a censurar las acciones del pueblo mismo que encabeza el protagonista. El punto de partida de Clotaldo es que el monarca es «absoluto dueño» (v.

${ }^{10}$ Ruano de la Haza, 1992, p. 85. 
2355). El rey, considerado como fons honoris por estar más cerca de la divinidad en la pirámide estamental, no puede ser cuestionado, es un acto de laesa majestad cualquier acción en su contra.

El planteamiento de Segismundo, al hacer partícipe del honor al pueblo, tiene una doble vertiente: por un lado, condescender con la moral política del privado significaría aceptar que él también es traidor; por otro, la participación generalizada del honor es un testimonio de que la sociedad en su conjunto gira en torno a dicho valor.

Ahora bien, ¿por qué Segismundo no considera la lucha contra el soberano un acto de traición? Incluso dentro del absolutismo la única vía que garantiza la estabilidad social es la ley. Sin embargo, Basilio la ha violentado al negar el derecho de sucesión al príncipe. Circunstancia que el dramaturgo aclara en la edición madrileña cuando Segismundo especifica que la grandeza «me da la naturaleza / por derechos de su ley» (vv. 1510-1511); mientras que en la versión de Zaragoza expresa: "es propria de mi nobleza, / por su decreto y su ley» (vv. 1520-1521). En este caso la legalidad se circunscribe a un concepto ideológico del estamento dominante, en tanto que la corrección se dirige al hombre en general. Es evidente que Calderón, al referirse a la lex naturalis, en la que se fundamenta la ley humana de acuerdo con la teoría política de Santo Tomás - legado del estoicismo-, es más preciso en la edición aprobada en 1635. Es decir, la ley eterna se conoce por la ley natural y se manifiesta en la ley humana, que es la que permite el buen funcionamiento social. Dado que la ley del monarca, quien busca su beneficio y no el común, no concuerda con la natural, estamos frente a la corrupción de la ley. De ahí que su disposición de colocar en el trono a sus sobrinos carezca de validez y sea cuestionable por los vasallos inconformes. En síntesis, el rey actúa contra el derecho positivo. Causa de que en la culminación de la obra se le presente deshonrado.

En el texto zaragozano Segismundo no reconoce a Basilio como su monarca, expresa «vuestro Rey» al dirigir su parlamento al «Campo ilustre de Polonia» (v. 3168), mientras el soberano permanece arrodillado; además aconseja, "Sirva el honor de escarmiento», y de ejemplo el ver al rey postrado. La humillación del monarca es verdaderamente patética y rigurosa, pues es exhibido frente al pueblo que participó en la batalla y al que el príncipe concede el derecho al honor, en este caso a no ser considerado traidor, ya que permanece dentro de 
los términos de la legalidad. En la obra se desdeña el acceso diferenciado o gradual al honor: no existe "honor segundo" como sostienen Basilio y Clotaldo (Z, vv. 2395, 2435), porque no hay tampoco un honor primero, privilegiado, en tanto violente la ley ${ }^{11}$.

El príncipe cuestiona la existencia de una moral absoluta impuesta por el estamento dominante encabezado por el monarca, quien corrompe la ley, lo que no se traduce en una ausencia de la moral. Todo lo contrario. Aunque Segismundo todavía no se ha transformado por completo, su apertura política proclama el sentido de nacionalidad, a lo que él agrega un reconocimiento social igualitario que se deriva del cumplimiento de la ley. Todos comparten el derecho al honor significa un código de valores que es expresado con acciones y que, obviamente, no implica la posesión de riquezas. De inicio, estamos frente a un sentido del concepto asociado a la virtud. En palabras de Claude Chauchadis: «L'excellence en vertu, critère moral, permet donc théoriquement à tout homme, quel que soit son rang social, d'acquérir sa part d'honneur» ${ }^{12}$. Se busca o exige romper el monopolio de la aristocracia sobre los códigos de valor, ya que deben fundarse en la virtud, no se disocia la moral de la política de manera oportunista como propone Maquiavelo.

Una vez que Segismundo y Basilio se reencuentran, el nuevo soberano expresa como objetivo: «Pues en señal de que aguarda / mi honor inmensas vitorias / empiezo con la más alta, / que es vencerme a mí» (vv. 3249-3252). En la edición de Madrid hay una variante trascendente: «Pues que ya vencer aguarda / mi valor grandes vitorias / hoy ha de ser la más alta / vencerme a mí» (vv. 3255-3258). En ambas se trata de la capacidad racional de dominarse a sí mismo,

${ }^{11}$ Dichos versos del rey y el privado aluden a las dos oportunidades que ha tenido el protagonista de vivir en una situación de poder (en el palacio y libre dirigiendo al ejército); la segunda intención es la lucha por el trono en un acto de traición. En este punto es necesario reconsiderar el cambio propuesto por Ruano de la Haza en la edición madrileña, pues el manuscrito dice: «A segunda intención, a horror segundo». Verso que podría ser una modificación del dramaturgo en el sentido matizado que se otorga al honor en la edición madrileña. Podría tratarse de una precisión señalar que un primer «honor» se refiere a colocar a Segismundo en el palacio, lo que se convirtió en un primer «horror» dada su conducta pasional; y otro ya convertido en «horror», que es verlo al frente del ejército.

12 Chauchadis, 1984, p. 17. 
pero la versión de Zaragoza resalta un factor de integración muy español: la cuestión del honor. La de Madrid amplía su perspectiva a la capacidad de cualquier hombre sobre su propio ser, sin importar la geografia.

Por otro lado, es preciso considerar que Segismundo no desconoce la trascendencia de la lealtad y el honor femenino; recordemos que en versos previos, ante la decisión de Clotaldo, el protagonista responde con ira, misma que reprime:

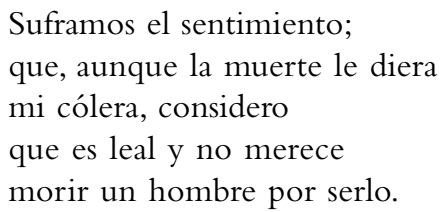

(vv. 2337-2341)

La ponderación de la ley del homenaje evita la muerte del privado. Asimismo, en relación con la deshonra de Rosaura, cuando ésta le solicita ayuda, una de sus reflexiones determinantes de su conducta, similar en la versión madrileña, es sobre la función del gobernante:

Pues más a un príncipe toca

dar honor que no quitarle.

¡Vive Dios, que de su honra

he de ser conquistador

aún más que de mi corona!

(vv. 2993-2997)

En esta fase de la obra, pues, hay principios éticos que le conciernen: Segismundo coloca por encima del poder, la moral. Por lo demás, la misma apertura social ${ }^{13}$ expresada a Clotaldo ante los soldados, a quienes ha llamado "Amigos», será confirmada al dirigir el último parlamento largo al «Campo», es decir al ejército y al pueblo. Las explicaciones sobre la actitud de su padre, que durante todo el discurso ha permanecido de rodillas, las ofrece a los soldados, aunque están pre-

13 En mi artículo «Aspectos ideológicos de la versión de Zaragoza de La vida es sueño", expongo una idea distinta sobre este punto. Sin embargo, la relectura del texto me inclina a modificar mi punto de vista. Ver Campbell, 2001. 
sentes miembros de la corte. Manifiesta, pues, un respeto hacia el pueblo («vulgo» para el Soldado). Sin embargo, a pesar de que en este texto no se produce una reflexión sobre el sometimiento del rey, al postrarse ante Basilio lo llama "padre", mientras que en la edición de Madrid le dice «señor». Además, la solidaridad con los vasallos no incide en su determinación de castigar al traidor y dar una lección pública. Así pues, el príncipe valora la lealtad, y en consecuencia castiga la traición, el principio de la honra, reconoce al padre-rey como máxima autoridad, y conserva una línea de respeto hacia la población, lo cual no puede ser denominado como maquiavelismo.

Una cuestión filosófico-política de gran importancia que mantiene un estrecho nexo con la edición madrileña es la relación con el pensamiento neoestoico y tacitista. En su conversión, Segismundo domina sus pasiones mediante la razón y se vuelve un príncipe virtuoso, calificado como prudente por el mismo Basilio. Por otro lado, afirma:

La fortuna no se vence con injusticia y venganza; con prudencia y con valor, sí; y así, quien vencer aguarda, ha de esperarla constante cuerpo a cuerpo y cara a cara $[\ldots]$ Sentencia del cielo fue; y porque quiso escusarla, sin valor y sin prudencia, no pudo; y hoy mi constancia ha de poder, siendo menos.

(Z, vv. 3220-3236)

porque antes se incita más.

a su fortuna, ha de ser con prudencia y con templanza. [...] por más que quiso estorbarla él, no pudo; y podré yo, que soy menor en las canas, en el valor y en la ciencia, vencerla.

(M, vv. 3214-3241) 
Parece mucho más abundante, en términos morales, la versión de Zaragoza que la de Madrid, ya que se requiere valor, prudencia y, la virtud que logra vencer al hado, constancia. En su libro sobre la Constancia Lipsio la define como «un recto y inmutable vigor de ánimo, que no se ensobervece, ni abate con los sucesos exteriores, o fortuitos» ${ }^{14}$. Su compañera es la razón, mientras que de las pasiones y la opinión es la liviandad.

En el texto zaragozano, amén de la deshonra de Basilio frente al pueblo, Segismundo lo presenta como un cobarde, incapaz de enfrentarse a la fortuna con valentía, ya que trató de excusarla; por el contrario se autodefine con un vigor anímico superior. En la edición de Madrid, donde Segismundo se dirige a la corte y no hace referencia al honor («Sirva de ejemplo este raro / espectáculo», vv. 31283129), habla de la necesidad de prudencia, pero patentiza mayor humildad al reconocer que su experiencia (edad), su valor y conocimiento son menores.

La alusión a la constancia como virtud fundamental con la que se debe enfrentar a la fortuna, disminuye la personalidad del rey en la versión de Zaragoza, pues vuelve a remitirse a su valentía que hemos visto abatida y devaluada, de ahí que Calderón opte, en la edición madrileña, por quedarse sólo con la prudencia, virtud capital del tacitismo y del neoestoicismo. La conversión de Segismundo es mucho más coherente, sólida y, sobre todo, convincente, en el texto de Madrid, donde el valor femenino no se degrada y la ponderación de los verdaderos bienes implica el rechazo de lo material. Asimismo, la derrota de Basilio significa mayor dificultad al tener como guía del ejército a un rey decidido, y no a un monarca autodenigrado y autocompasivo que duda de su capacidad para triunfar en la batalla.

Por otra parte, el hecho de nombrar a Clotaldo como su privado, lo que no ocurre en la edición madrileña, puede tener dos lecturas: hay una continuidad política, y por lo tanto el tacitismo se relativiza o, dado que el personaje ha sido fiel seguidor del rey y ha obrado con lealtad, Segismundo pretende garantizar la misma actitud bajo su reinado. No obstante, el lector/espectador ha tenido un antecedente significativo de esa relación. Cuando el príncipe solicita ayuda a Clotaldo le dice: «que tú has de ser norte y guía / de quien fie mis aciertos»

${ }^{14}$ Lipsio, Libro de la constancia, p. 11. 
(vv. 2320-2321). Palabras que permiten suponer una gran influencia del privado en el destino político de Polonia. Quizá esa sea la causa de que, aunque dichos versos están en la versión madrileña, Clotaldo no fuera elevado a tal rango.

Es preciso notar, no obstante, que el concepto de prudencia es muy significativo en Clotaldo: «Consejo me dé el prudente; / éste a los cielos le pido» (vv. 976-977). La relación de esta virtud con la divinidad proporciona la medida del valor que le otorga el personaje y que es esencial para el tacitismo. Segismundo responde al Soldado 1: «el que es prudente / del que fue traidor se guarda» (vv. 3280-3281); y Basilio, al oír esto, exclama: «iGran prudencia!» (v. 3282). Astolfo aprueba la petición del rey basado en uno de los pilares de la ideología dominante: "pues le basta ser tu hijo / para que prudente reine / de mil perfeciones rico» (vv. 845-847). La herencia biológica de la virtud es cuestionada, pues Segismundo ha logrado vencerse por sus propios méritos y así lo enuncia cuando da la mano a Estrella. De cualquier forma, la ponderación de la prudencia y la práctica de ella por el nuevo rey se relacionan con el tacitismo.

Si bien en ambas versiones encontramos un Segismundo regido por las pasiones en un primer momento, vemos que ha sido posible su transformación; sostiene Lipsio al respecto:

Porque aunque el ánima esté muy inficionada y corrompida del pecado del cuerpo, y del contagio de los sentidos, todavía retiene profundamente ciertos rastros de su nacimiento y resplandecen en ella unas centellas de aquel su primero y puro fuego ${ }^{15}$.

En términos de Evangelina Rodríguez Cuadros ${ }^{16}$ podemos afirmar que el príncipe pasa «de reverencia iluminadora de los sentidos y renuncia de los mismos para seguir sosteniendo la parábola de la razón».

La tendencia ideológica de la versión de Zaragoza se encuentra dirigida al concepto del honor: deshonra femenina, honor como lealtad absoluta, honor como victoria y reinado de Segismundo, deshonor de Basilio. La edición de Madrid tiene un carácter más universal, sin que ello niegue ciertos lineamientos políticos y filosóficos comu-

15 Lipsio, Libro de la constancia, p. 14.

16 Rodríguez Cuadros, 1997, p. 157. 
nes: se sigue el planteamiento neoestoico y tacitista introducido por Justo Lipsio. No obstante, en la edición de Zaragoza se percibe más claramente la influencia lipsiana del Libro de la constancia, mientras que en la madrileña ésta se matiza, con lo que se hace más patente la presencia de otros estoicos, Séneca en particular, y de Tácito. El maquiavelismo del rey se suaviza porque el personaje pierde fuerza. Su decisión de quedar invicto se disuelve al emplearse el mismo término en varias ocasiones: Segismundo habla de su «valor invicto» (v. 2300), («inmenso valor» en M) Rosaura se refiere a su «invicta fama» (v. 2906), y antes ha dicho al protagonista «tu reino invicto restaura» (v. 2900).

Respecto al pueblo es notoria la distinción que se establece en la edición de Madrid donde Segismundo refleja una perspectiva política clara al tratarlo como "vasallos», mientras que para el resto de los personajes es «vulgo». En el texto de Zaragoza no hay esta diferencia, ya que Clotaldo y Rosaura se refieren al pueblo como "vasallos»; en $\mathrm{M}$ el primer caso no existe y el otro lo modificó por "soldados». Estrella, al definir a ambos ejércitos como "tumulto», dice: «fiero, soberbio, ciego y atrevido" (v. 2409), igualando a los dos bandos, lo que no figura en la edición de Madrid. Basilio habla del «vulgo» que se atreve contra él; en la de Madrid lo califica de soberbio y atrevido. Antes de iniciar su último parlamento, en la versión de Zaragoza, el príncipe pide al ejército:

En tanto que vuestro Rey
veis en pena tan extraña,
dad a la cólera treguas,
suspended todos las armas.
Campo ilustre de Polonia...

(vv. 3164-3168)

Salta a la vista una marcada tendencia y respeto hacia el pueblo: mayor intervención, polémica con Clotaldo, defensa de su honor, denominación de «vasallos» por los cortesanos, de «amigos» por el príncipe, discurso final dirigido a éste. La búsqueda del bienestar colectivo en el ejercicio del poder, es un resultado que se anuncia. Los cuatro primeros versos no aparecen en la versión madrileña, y en el último se dirige a la corte. Las modificaciones permiten diferenciar a las claras las dos perspectivas sobre el Estado: la maquiavélica de Basilio, cuyas acciones responden a meros intereses personales y no considera 
como vasallos al pueblo, y la tacitista de Segismundo, quien obra por el bien común.

La conducta y carácter de los personajes es mucho más afinada en la edición de Madrid, cada uno sigue una línea coherente con una perspectiva ideológica. Así, aunque Basilio también piense en términos individuales, es un hombre frío y decidido; y Clotaldo es fiel representante de dichos intereses. En cuanto al príncipe, sus pasiones están menos relacionadas con el erotismo y su transformación hacia la racionalidad se presenta más claramente. En ambas versiones se ponen en práctica los postulados del maquiavelismo; hay una conversión neoestoica del protagonista, por sus propios méritos, que lo lleva a obrar por el bien común, habiendo considerado el antimodelo del rey como ejemplo de lo que hay que evitar, y enarbolando la prudencia como máxima virtud, de acuerdo con la propuesta del tacitismo. Las variantes, pues, muestran una mayor afinación, elegancia y coherencia, universalismo, y no un cambio político-filosófico. 


\section{Bibliografía}

Alcalá-Zamora, J. N., La reflexión política en el itinerario del teatro calderoniano, Madrid, Real Academia de la Historia, 1989.

Calderón de la Barca, P., La vida es sueño, ed. J. M. Ruano de la Haza, Madrid, Castalia, 1994.

Campbell, Y., "Aspectos ideológicos de la versión de Zaragoza de La vida es sueño", en Actas del $V$ Congreso de la Asociación Internacional Siglo de Oro (Münster, 1999), ed. C. Strosetzki, Madrid / Frankfurt am Main, Iberoamericana / Vervuert, 2001, pp. 260-266.

Chauchadis, C., Honneur, morale et société dans l'Espagne de Philippe II, Paris, Éditions du CNRS, 1984.

Covarrubias, S. de, Tesoro de la lengua castellana o española, ed. I. Arellano y R. Zafra, Madrid, Iberoamericana, 2006.

Lipsio, I., Libro de la constancia de Justo Lipsio, trad. J. Baptista de Mesa, Sevilla, 1626.

Maquiavelo, El príncipe, pról. S. Fernández Campo, ed. M. López Suárez, Madrid, Ediciones Temas de Hoy, 1994.

Rodríguez Cuadros, E., "Calderón entre 1600 y 1640: todo intuición y todo instinto", en La década de oro en la comedia española: 1630-1640. (Actas de las XIX Jornadas de teatro Clásico, Almagro, julio de 1996), ed. F. B. Pedraza y R. González Cañal, Ciudad Real, Universidad de Castilla-La Mancha, 1997, pp. 127-158.

RuANO DE LA HAZA, J. M., "Introducción» a La primera versión de "La vida es sueño», de Calderón, Liverpool, Liverpool University Press, 1992, pp. 8-58.

SÉneCA, De los beneficios y la gratitud que se les debe, Epístolas morales a Lucilio, ed. I. Roca Meliá, Madrid, Gredos, 1994. 
